\title{
The Effect of Foliar Spray Fertilizers on the Tolerance of Hordeum vulgare to UV-B Radiation and Drought Stress
}

\author{
I. JANUŠKAITIENE** and G. KACIENE \\ Department of Environmental Science, Vytautas Magnus University, \\ Vileikos 8-125, 44404 Kaunas, Lithuania
}

(Received 31 October 2016; Accepted 26 January 2017;

Communicated by S. Gottwald)

\begin{abstract}
The impact of foliar spray fertilizers (Aton Az) on the resistance of spring barley (Hordeum vulgare L.) against to individual and combined UV-B radiation and drought effects were investigated. Barley seeds were sown in pots prepared with neutral $\mathrm{pH}$ peat substrate. When the $2^{\text {nd }}$ true leaf unfolded, i.e. 7 days after germination, the first spray with microelement and free amino acid fertilizers was carried out; two days after this application, the different irradiation ( 1 and $\left.3 \mathrm{kJm}^{-2} \mathrm{~d}^{-1}\right)$ UV-B doses and drought effects were started. Exposure lasted for 6 days. The main characteristics of all investigated indicators were assessed at the end of exposure. The largest positive effects of fertilizers on the photosynthetic rate and water use efficiency of barley were found solely under the impact of drought. Foliar spray fertilizers decreased oxidative stress injury in the leaves by decreasing the malondialdehyde content under solely effects of drought and UV-B radiation, while under the combined effect of the mentioned stress factors, the changes were statistically insignificant. A stronger positive impact of foliar fertilization was detected on the content of photosynthetic pigments $(a$ and $b$ ) at solely UV-B radiation effect than at combined effect of investigated factors, when significant changes were detected only in individual cases.
\end{abstract}

Keywords: barley, drought stress, foliar spray fertilizers, photosynthetic rate, UV-B radiation

\section{Introduction}

Foliar application of fertilizers has potential benefits, including the possibility of supplying nutrients to the plant when soil conditions restrict root uptake or during periods of rapid growth (Del Amor and Cuadra-Crespo 2011). Also, foliar application of ameliorative and anti-stress substances is one method that may decrease the harmful effects of stress on plants (Ibrahim and Ramadan 2015). The application of amino acids was found to have a positive effect on plant growth which overcomes the harmful effect of some environmental stresses such as drought. The importance of amino acids came from their wide use for the biosynthesis of a large variety of non-proteinic nitrogenous materials, i.e. pigments, vitamins, coenzymes, and purine and pyrimidine bases. Studies have proved that amino acids can directly or indirectly influence the physiological activities of plant growth and yield (Hammad and Ali 2014; Shafeek et al. 2016).

*Corresponding author; E-mail: irena.januskaitiene@vdu.lt 
The effect of drought stress and UV-B radiation on crop plants varies depending on the intensity of stress and the crop growth stage (Singh et al. 2014). The effect of UV-B on plants depends on radiation rates and wavelength, and has a cumulative character; the longer the time of exposure, the greater the effect of its action (Bandurska et al. 2013). Some of the deleterious effects of UV-B radiation on plants include DNA damage, dilation and disintegration of cellular membranes, photooxidation of leaf pigments and phytohormones, and inhibition of photosynthesis (Reddy et al. 2013). The UV-B protective mechanism in plants involves photoreactivation to repair DNA damage, accumulation of UV-B absorbing compounds (e.g., phenolic compounds) and waxes in the leaf epidermis to partially block UV-B radiation (Singh et al. 2014). Therefore, the plant responses are not stress responses but are rather associated with UV-B protection or amelioration of damage (Bandurska et al. 2013).

Drought stress causes a wide range of biochemical and physiological changes that negatively affect plant development and productivity. Water deficit induces stomatal closure, limits $\mathrm{CO}_{2}$ uptake by leaves and reduces the potential activity of Calvin cycle enzymes, particularly Rubisco, due to the absence of substrate (Nawaz et al. 2015). The photosynthetic apparatus can be damaged by reactive oxygen species (ROS) generated when stomata are closed, reducing photosynthesis and growth (Sharma et al. 2012). Some of the plant responses to water deficit are directly triggered by changes in tissue water status, while others are due to changes in the level of plant growth regulators. A decrease in the level of auxins, gibberellins and cytokinins and an increase of abscisic acid, jasmonic acid, ethylene, and salicylic acid levels are often observed in drought stressed plants (Pospisilova 2003).

In nature, abiotic stresses often interact to produce combined impacts on agroecosystems. Understanding the interactive effects of stress factors is particularly important when their combined effect cannot be predicted based on evidence from single stressor studies (Singh et al. 2013). Moreover, experiments on the interactive effect of drought stress and UV-B radiation on plant growth and development are scarce (Bandurska et al. 2013). Reports about the influence of foliar application on the combined effect of the mentioned factors are even rarer. For these reasons, the aim of this work was to study the influence of foliar application of microelements and amino acids on the physiological and biochemical parameters of barley, its growth under combined UV-B radiation and the effect of drought stress.

\section{Material and Methods}

\section{Plants' growing conditions and experimental design}

Spring barley (Hordeum vulgare L., cv. 'Aura') was chosen for investigation. Experiments were carried out in a vegetation room with a controlled environment. The growth conditions in the phytotron chamber were: photoperiod of $14 \mathrm{~h}$, average temperature of $20-25{ }^{\circ} \mathrm{C}$, and relative humidity of $60 \%$. Philips Master Green Power CG T $600 \mathrm{~W}$ lamps, with a light intensity at the plant level of 14,000 Lx, provided light. 
Barley (15 individual plants per pot) was sown in a neutral ( $\mathrm{pH}$ 6.0-6.5) peat substrate in $0.5 \mathrm{~L}$ pots $(10 \mathrm{~cm}$ in diameter). In each treatment, there were three pot replications. When the $2^{\text {nd }}$ true leaf unfolded, i.e. at leaf development stage (Meier 2001) the first spray on the leaves was carried out with fertilizers containing microelements and free amino acids (Aton AZ: $5.8 \%$ free amino acids, $1.2 \% \mathrm{Ca}, 0.1 \% \mathrm{~B}, 1.1 \% \mathrm{Fe}, 0.8 \% \mathrm{Mn}, 0.1 \% \mathrm{Mo}$ and $1.3 \% \mathrm{Zn}$ ). According to the manufacturer's recommendations, $0.1 \%$ concentration solution was made. Within 2 days after the first fertilizer application, the different irradiation ( 1 and $3 \mathrm{~kJ} \mathrm{~m}^{-2} \mathrm{~d}^{-1}$ ) UV-B doses and drought stress were started. UV-B radiation was provided by UV-B fluorescent tubes TL 40W/12 RS UV-B Medical (Philips); the doses were chosen according to the previous experiments (Brazaityte et al. 2006). The moisture of the substrate was measured every day with a soil moisture meter Delta-T HH2 (Cambridge, UK) and to ensure that the moisture of well-watered (WW) and drought stressed (DS) treatment variants were approximately $85 \%$ and $55 \%$, respectively, less or more water was added every day. Experimental exposure lasted for 6 days. The second and third fertilizer spray applications were made on the $3^{\text {rd }}$ and $5^{\text {th }}$ days of exposure. The main characteristics of all investigated parameters were assessed at the end of exposure, i.e. on the $6^{\text {th }}$ day.

\section{Gas exchange measurements}

Gas exchange parameters were measured with a portable photosynthesis system LI-6400 (LI-COR, USA). Net photosynthetic rate $\left(\mu \mathrm{mol} \mathrm{CO} \mathrm{CO}_{2} \mathrm{~m}^{-2} \mathrm{~s}^{-1}\right)$, intercellular $\mathrm{CO}_{2}$ concentration ( $\mu \mathrm{mol} \mathrm{CO}_{2}$ mol air-1), transpiration $\left(\mathrm{mmol} \mathrm{H}_{2} \mathrm{O} \mathrm{m}^{-2} \mathrm{~s}^{-1}\right)$ and water use efficiency ( $\mu \mathrm{mol} \mathrm{CO}_{2} \mathrm{mmol} \mathrm{H}_{2} \mathrm{O}^{-1}$ ) of the $3^{\text {rd }}$ fully expanded leaves were registered every 3 seconds for 5 minutes in five randomly selected plants of each treatment variant; from these data, a mean of daily measured indices was calculated. Environment conditions during measurements were: air flow rate $-400 \mu \mathrm{mol} \mathrm{s}{ }^{-1}$, block and leaf temperature $-24{ }^{\circ} \mathrm{C}, \mathrm{CO}_{2}$ concentration in sample cell $-350-400 \mu \mathrm{mol} \mathrm{CO} \mathrm{mol}^{-1}$, relative humidity in sample cell $-30 \%$, and lightness in quant $-120 \mu \mathrm{mol} \mathrm{m}^{-2} \mathrm{~s}^{-1}$.

\section{Determination of photosynthetic pigments}

The third fully expanded leaves were harvested and photosynthetic pigments were analyzed using a Genesys 6 spectrophotometer (ThermoSpectronic, USA) in 100\% acetone extracts prepared according to Wettstein's (1957) method. Photosynthetic pigments were expressed in $\mathrm{mg} / \mathrm{g}$ of fresh weight.

\section{Determination of malondialdehyde (MDA)}

Concentration of MDA, the end-product of lipid peroxidation, was used as a biomarker of membrane oxidative damage. MDA content was determined by reaction with thiobarbituric acid according to Blokhina et al. (2003). 


\section{Determination of dry weight}

At the end of the experiment, the plants were harvested and dried in an oven at $60{ }^{\circ} \mathrm{C}$ until constant dry foliage biomass was obtained. The biomasses were expressed in $\mathrm{mg} /$ plant.

\section{Statistical analysis}

ANOVA was used to determine the effects of foliar spray, UV-B and drought effect. For independent variables, comparisons were made using the Student's $t$ - and $U$-tests. All analyses were performed by STATISTICA and the results were expressed as mean values and respective confidence intervals $(\mathrm{CI})$ with a significance level of $5 \%(p<0.05)$.

\section{Results}

\section{Gas exchange parameters}

Photosynthetic rate decreased in barley plants at both watering variants exposed to UV-B radiation (Fig. 1A). The highest $94.5 \%(p<0.05)$ decrease of photosynthetic rate was detected for drought stressed barley plants, compared to the control. The combined effect of UV-B and drought stress was higher than the individual effect of UV-B. Foliar fertilization had a positive effect on the photosynthetic rate of stressed barley, but was statistically significant $(p<0.05)$ only for WW and 1 and $3 \mathrm{~kJ}$ UV-B exposed, and solely drought
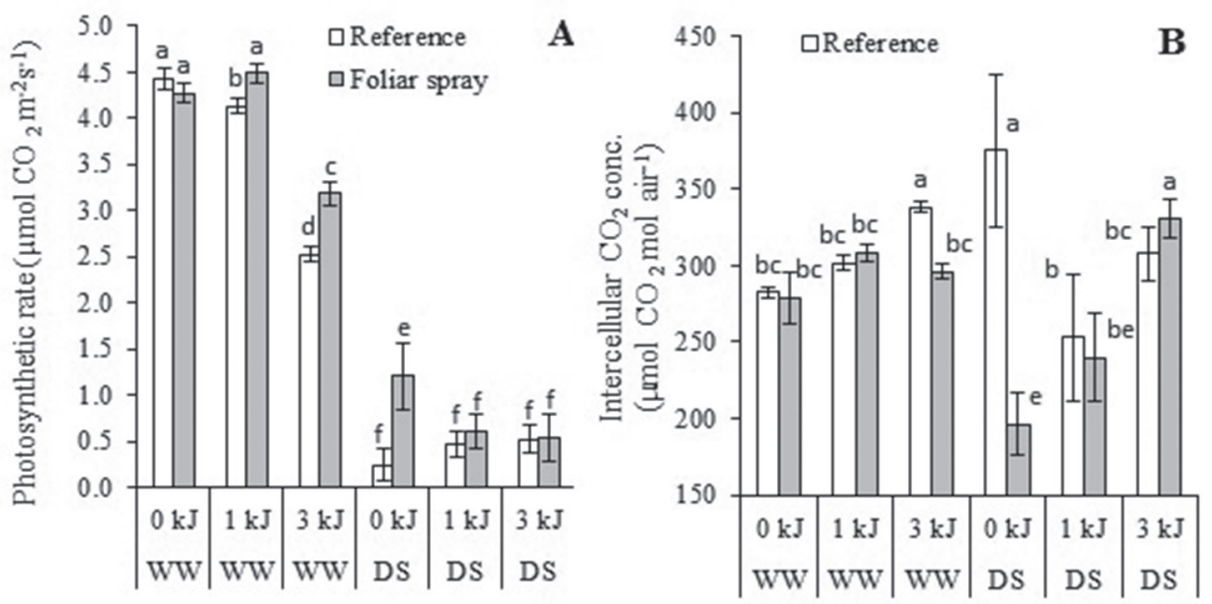

Figure 1. The effects of foliar spray fertilizers on photosynthetic rate (A), intercellular $\mathrm{CO}_{2}$ concentration (B), transpiration rate $(\mathrm{C})$, water use efficiency (D), chlorophyll $a(\mathrm{E}), b(\mathrm{~F})$, carotenoids $(\mathrm{G})$ and chlorophyll $a$ : chlorophyll $b$ ratio $(\mathrm{H})$ of well-watered (WW) and drought stressed (DS) and with 1 and $3 \mathrm{~kJ}$ UV-B exposed barley plants. The values are means $\pm \mathrm{CI}_{0.05}$; significant differences $(p<0.05)$ between treatments are denoted with different letters 

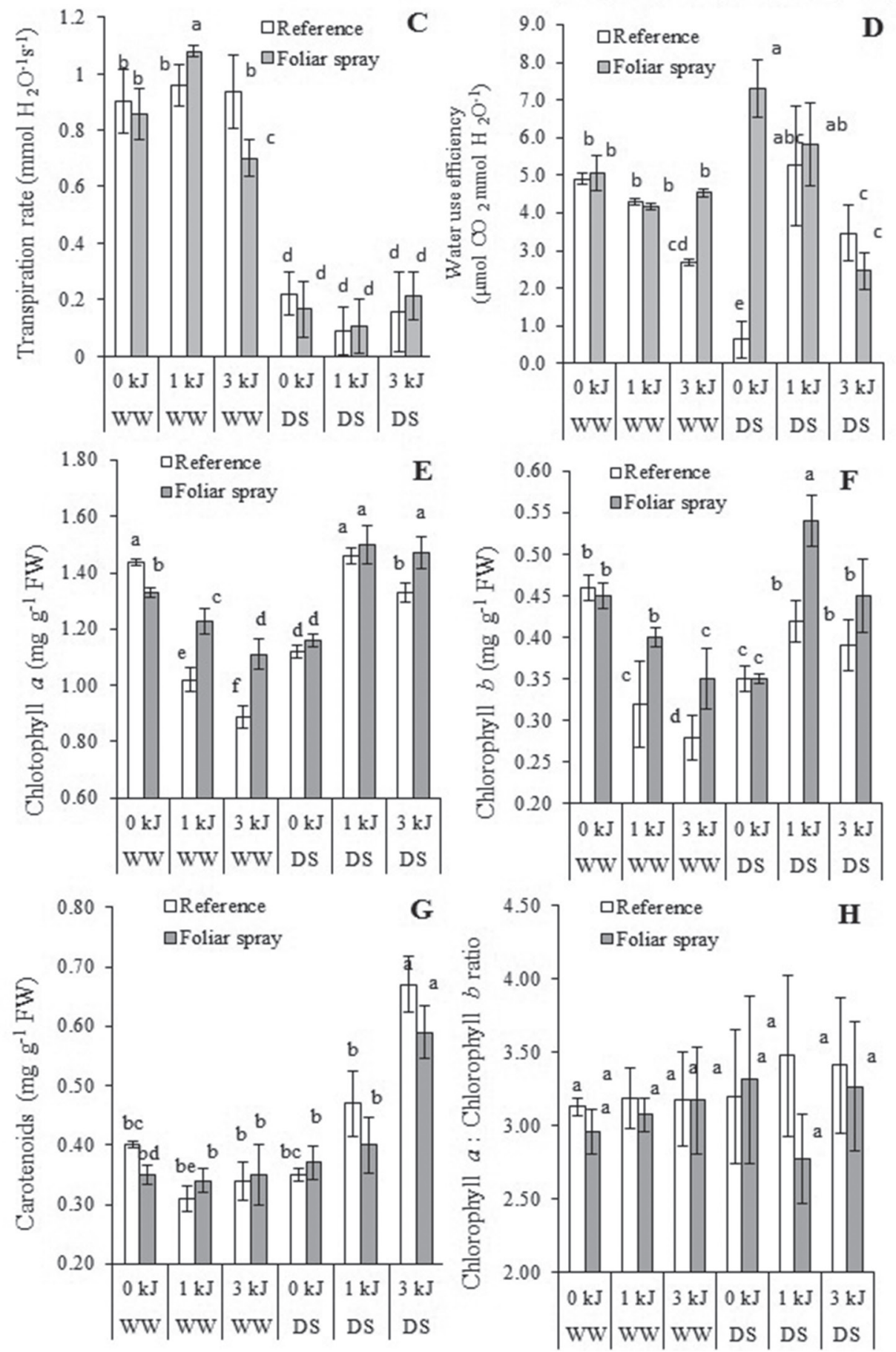

Figure 1 (cont.) 
stressed plants, when the photosynthetic rate with foliar spray treated plants was $8.6 \%$, $26.1 \%$ and 5 times higher, respectively, compared to the reference treatment.

Intercellular $\mathrm{CO}_{2}$ concentration increased in barley of well-watered plants and those treated with UV-B radiation (Fig. 1B), while intercellular $\mathrm{CO}_{2}$ concentration in drought stressed and treated with UV-B plants decreased in comparison to the reference treatment. Foliar fertilization significantly decreased intercellular $\mathrm{CO}_{2}$ concentration in wellwatered and exposed to $3 \mathrm{~kJ}$ barley plants and solely drought stressed ones by $12.5 \%$ $(p<0.05)$ and $47.7 \%(p<0.05)$, respectively, compared to the reference treatment.

The transpiration rate of well-watered plants was significantly higher than droughtstressed ones (Fig. 1C). Individual UV-B exposure did not have a statistically significant effect on the transpiration rate of barley plants. The combined effect of 1 and $3 \mathrm{~kJ} U \mathrm{UV}-\mathrm{B}$ and drought stress decreased the transpiration rate of barley plants by $88.4 \%(p<0.05)$ and $76.5 \%(p<0.05)$, respectively, compared to the control plants. Foliar fertilization increased transpiration in barley exposed to $1 \mathrm{~kJ}$ under WW conditions by $12.5 \%$ $(p<0.05)$ and decreased transpiration in barley exposed to $3 \mathrm{~kJ}$ under WW conditions by $25.2 \%(p<0.05)$ compared to the reference treatment.

The water use efficiency of well-watered barley plants decreased under increasing UV-B radiation (Fig. 1D), while the lowest water use efficiency of drought stressed plants was detected for plants that were not exposed to UVB. Under individual 1 and $3 \mathrm{~kJ}$ effect, water use efficiency decreased by $12 \%(p<0.05)$ and $45 \%(p<0.05)$, respectively, and under combined increased by $7.5 \%(p<0.05)$ and decreased by $29.2 \%(p<0.05)$, respectively, compared to the WW and non-UV-B exposed plants. Foliar fertilization had a strongly positive effect only on WW and with $3 \mathrm{~kJ}$ UV-B exposed, and only drought stressed plants, when water use efficiency with foliar spray treated plants was $69 \%$ $(p<0.05)$ and 11 times $(p<0.05)$ higher, respectively, compared to the reference treatment.

\section{Photosynthetic pigments}

Under well-watered conditions, the contents of photosynthetic pigments decreased after UV-B exposure, while under drought stress, the photosynthetic pigments content increased compared to the non-exposed to UV-B (Fig. 1E-G). The positive effect of foliar fertilization was the highest for WW plants, when the content of pigments was $22 \%$ $(p<0.05)$ and $25 \%(p<0.05)$ higher compared to the reference treatment. The combined effect of UV-B and drought stress foliar fertilization was not so strong and statistically significant only for $3 \mathrm{~kJ}$ UV-B and the drought stress variant. The highest increase of carotenoids was detected for combined $3 \mathrm{~kJ}$ UV-B and drought stress effect.

\section{Malondialdehyde (MDA)}

With increasing intensity of stress, the content of MDA in barley leaves was likewise increased (Fig. 2A). MDA concentration under solely $1 \mathrm{~kJ}$ UV-B effect was twice higher than in WW and non-UV-B exposed (control) plants, and under combined $3 \mathrm{~kJ} \mathrm{UV-B}$ and 

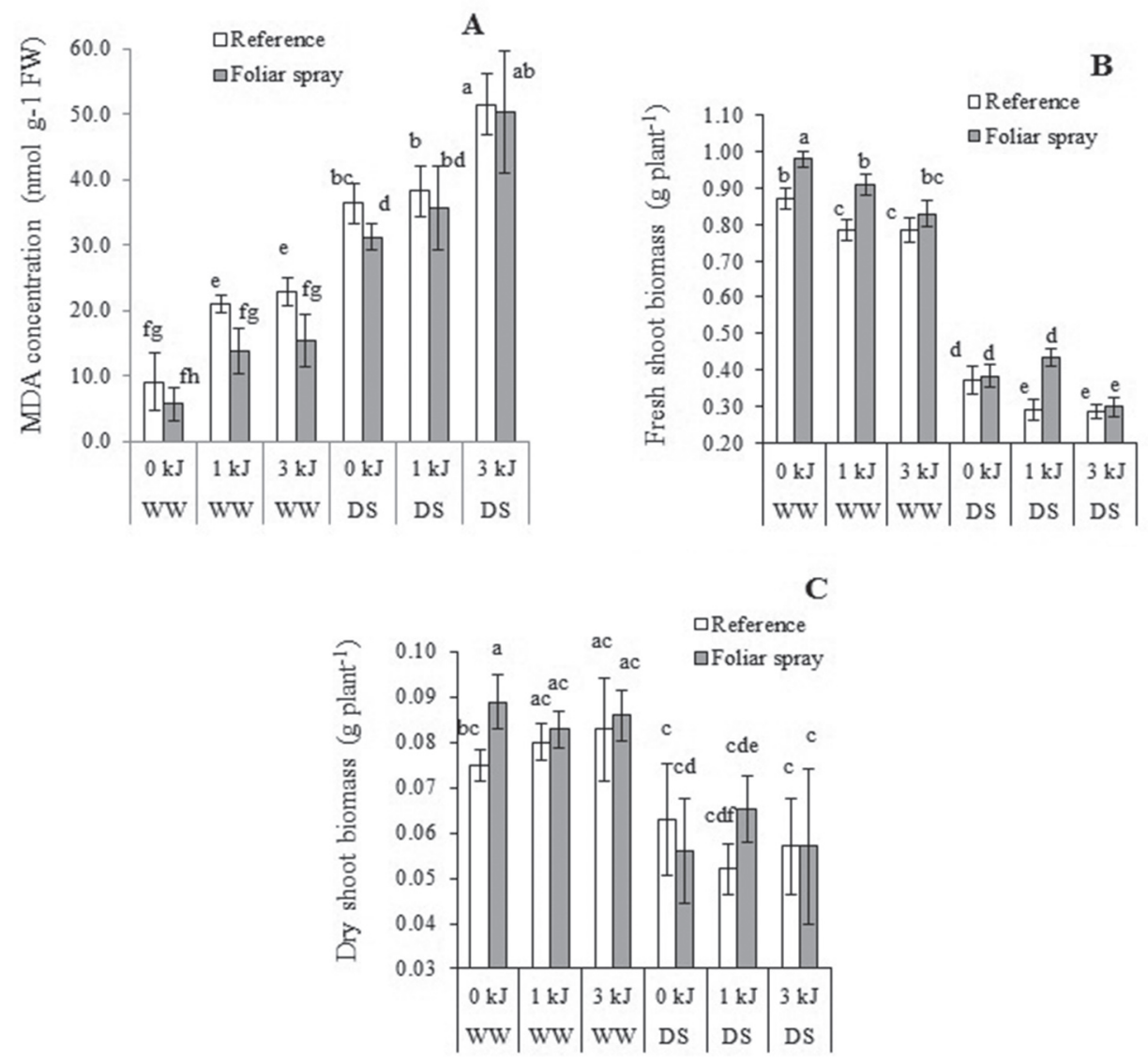

Figure 2. The effects of foliar spray fertilizers on the content of malondialdehyde (MDA) (A), fresh (B) and dry $(\mathrm{C})$ shoot biomass of well-watered (WW) and drought stressed (DS) and with 1 and $3 \mathrm{~kJ}$ UV-B exposed barley plants. $\mathrm{FW}$ - fresh weight; the values are means $\pm \mathrm{CI}_{0.05}$; significant differences $(p<0.05)$ between treatments are denoted with different letters

drought stress it increased 5.7 times compared to the control. Foliar fertilization had a positive effect on oxidative stress formation, and MDA concentration in barley leaves after foliar fertilization decreased, but was only statistically significant under individual 1 and $3 \mathrm{~kJ}$ UV-B and individual drought stress effects, when it decreased by 35, 33 and 14\% $(p<0.05)$, respectively.

\section{Biomass parameters}

The highest changes of fresh and dry shoot biomass were detected under drought stress effect (Fig. 2); fresh biomass decreased in barley at both watering variants exposed to UV-B radiation (Fig. 2B). Foliar fertilization had a positive effect on fresh biomass of 
UV-B stressed barley, but was statistically significant $(p<0.05)$ only for WW and with $1 \mathrm{~kJ}$ UV-B exposed, and combined $1 \mathrm{~kJ}$ UV-B and drought stressed plants, when fresh mass with foliar spray treated plants was $16.2 \%$ and $49 \%$ higher, respectively, compared to the reference treatment. The changes in dry biomass were the same as fresh; however, the statistically significant effect of foliar spray was detected only for combined $1 \mathrm{~kJ}$ UV-B and drought stressed plants (Fig. 2C).

\section{Discussion}

The foliar application of fertilizers is an effective agronomical practice in crop production, with a substantial influence on both yield and particularly grain quality (Ghasemi et al. 2013). In this study, there was investigated the effects of foliar spray fertilizers with free amino acids (Aton AZ) on photosynthetic parameters and growth of barley plants, which were exposed to UV-B radiation and drought stress. Results obtained showed that with foliar application, Aton AZ increased the photosynthetic rate, water use efficiency and biomass; also, foliar fertilization alleviated the negative effects of drought and UV-B radiation stress by decreasing the MDA content. The highest effect of investigated treatments was detected for drought stress $(F=18490.6, p<0.001)$, and the combined effect of UV-B radiation and drought stress significantly affected eleven parameters of the twelve investigated.

Plant responses to UV-B radiation and drought stress strongly depend on the duration and intensity of stress. UV-B radiation sometimes enhances resistance to water deficit and vice versa. Increased resistance can arise as a result of the activation of mechanisms of stress avoidance and tolerance (Bandurska et al. 2013). In this study, both solely and combined effects of UV-B and drought stress decreased the photosynthetic parameters of barley. Biophysical processes, which include $\mathrm{CO}_{2}$ transport through the leaf and stomata, and biochemical processes located in the chloroplast thylakoid membranes, stroma, mitochondria and the cytosol of the cell, determine the net rate of $\mathrm{CO}_{2}$ assimilation. Whereas the increase in intercellular $\mathrm{CO}_{2}$ level (in well-watered plants and treated with UV-B radiation) also indicates that net photosynthesis is reduced by reducing $\mathrm{CO}_{2}$ fixation by Rubisco, and can also include conditions in which enzymes of the Calvin cycle (other than Rubisco) limit the rate of photosynthesis (Januskaitiene 2011). Barley plants exposed to UV-B show both a decreased photosynthetic rate and increased intercellular $\mathrm{CO}_{2}$ concentration. This demonstrates for both stress factors an intense effect on dark reactions in photosynthesis as was mentioned above. On the other hand, the decreased photosynthetic rate in drought stressed plants could first be attributed to stomatal factor (Syvertsen and Garcia-Sanchez 2014). Gupta and Berkowitz (1987) suggested that under drought conditions, chloroplasts lose high amounts of $\mathrm{K}$ to further depress photosynthesis.

Foliar fertilization had a statistically significant $(p<0.05)$ positive effect on photosynthetic rate and water use efficiency of solely $3 \mathrm{~kJ}$ UV-B exposed, as well as solely drought stressed plants. It can be assumed, that with fertilization added amino acids, for example, proline, in addition intervened in the osmotic adjustment processes, also had other functions which helped to maintain a better status of the photosynthetic structure of cells, for example, protected enzymes and stabilized biological membranes (Gimeno et al. 2014). 
Literature indicates that UVB radiation has been shown to increase (Poulson et al. 2006), decrease (Qaderi et al. 2007) or have no effect on chlorophyll content (Newsham and Robinson 2009). It is known, that carotenoids are anti-stress pigments, shield chlorophyll from the miseries of light, excess of light or UV-B like harmful radiations and also act as antioxidants (Yadav et al. 2016). The highest increase of carotenoids was detected for combined $3 \mathrm{~kJ}$ UV-B and drought stress effect in this experiment too. In other and this research works an increment of carotenoids in barley plants during UV-B irradiation was not observed, because barley is less tolerant to UV-B than other plants (Blum et al. 2005). We can make an assumption that protective and adaptive reactions of above given type in barley emerged only under combined UV-B and drought stress conditions. On the other hand, the increase of carotenoids also might be explained by the increase of dehydration level of drought stressed plants.

Foliar fertilizers have helped to overcome the individual UV-B radiation induced stress, since the contents of chlorophylls $a$ and $b$ were higher $(p<0.05)$ in the sprayed barley leaves compared to the reference treatment (Fig. 1E-G). This confirms the foregoing hypotheses of a positive effect of amino acids on the membrane structure (Gimeno et al. 2014). The positive effect of foliar fertilization on drought stressed and exposed to UV-B plants was not so regular, i.e. under drought conditions and $1 \mathrm{~kJ}$ UV-B exposure foliar fertilization more increased chlorophyll $b$, while under drought conditions and $3 \mathrm{~kJ}$ exposure - chlorophyll $a$. Hammad and Ali (2014) got close results: the application of amino acids alleviated the negative effect of drought stressed plants and significantly enhanced the content of photosynthetic pigments in leaves.

Lipid peroxidation increased significantly when UV-B radiation increased and the changes were even higher under the combined effect of UV-B and drought stress (Fig. 2A). The exposure of plants to different adverse environmental conditions causes oxidative stress and, under these conditions, the mechanisms that contribute to de-energization of photosystems, such as photorespiration and the Mehler reaction, increase the production of $\mathrm{H}_{2} \mathrm{O}_{2}$ and, in some cases, $\mathrm{O}_{2}^{-2}$ (Del Amor and Cuadra-Crespo 2011). Our results showed decreased photosynthetic rates and growth (Fig. 1A, Fig. 2B, C). Foliar fertilization diminished the intensity of oxidative stress, and MDA concentration in barley leaves after foliar fertilization with amino acids decreased. The positive role of different implements with amino acids in abiotic stress tolerance was reported by Singh (1999), who mentioned that this type of fertilizers includes certain amino acids (for example, proline) and some ammonium compounds. These compounds are thought to play a pivotal role in plant cytoplasmic osmotic adjustment in response to drought stress. The results confirm those reported by Alaei et al. (2012) on wheat plants.

Biomass accumulation has decreased by increasing the intensity of the stress, and foliar fertilization significantly increased fresh and dry weight of barley exposed to $1 \mathrm{~kJ}$ UV-B, and $1 \mathrm{~kJ}$ UV-B and drought stressed plants (Fig. 2B, C). Foliar fertilization substances with amino acids enhance cell division and nutritional status, resulting in an increased number of leaves and dry weight of leaves, stems and roots. The application of this kind of fertilizer improves growth, which may be due to their role in increasing cell division and enlargement and forming more tissues and organs (Hammad and Ali 2014). The positive ef- 
fect of foliar fertilization may be due to the fact that it is a natural source of amino acids and most essential elements (Shafeek et al. 2016), which improved plant vegetative growth and overcome the inhibitory effect of drought stress (Hammad and Ali 2014).

The study reveals that the positive effect of foliar fertilization showed up on photosynthetic rate, water use efficiency and antioxidant system of solely $3 \mathrm{~kJ}$ UV-B exposed and solely droughts stressed plants, while under stronger combined effect of UV-B and drought stress the effectiveness of foliar fertilization was much weaker.

Based on the results the following conclusions can be made.

Drought stress had maximal effects and the highest changes of all investigated physiological, morphological, and biochemical parameters of barley $(F=18490.6, p<0.001)$. The most significant effects of exanimated combinations of stressors on investigated parameters were under combined UV-B radiation and drought stress conditions, when the impact of this combination of factors significantly affected eleven parameters of the twelve investigated.

The largest positive effect of foliar spray fertilizers on the photosynthetic rate of barley were under the solely impact of the drought. For example, the photosynthetic rate of fertilized barley was more than 6 times higher than in untreated plants $(p<0.05)$.

Foliar spray fertilizers decreased the MDA content under the individual effects of drought and UV-B radiation, compared to reference treatment $(p<0.05)$; under combined effects of these factors, the changes were statistically insignificant.

Foliar spray fertilization increased the content of photosynthetic pigments $a$ and $b$ at solely UV-B radiation effect $(p<0.05)$, while in the combined effect of the investigated factors, significant changes were detected only for individual cases.

\section{Acknowledgement}

Many thanks to Inga Ivankova, who assisted during the experiments and also permitted the use of her data for this publication.

\section{References}

Alaei, Y., Khanghah, A.M., Jafari, M., Khaneghah, A. 2012. Evaluation on leaf proline amount in three bread wheat cultivars in presence of two fertilizers containing amino acids in drought stress. World Appl. Sci. J. 18:1190-1192.

Bandurska, H., Niedziela, J., Chadzinikolau, T. 2013. Separate and combined responses to water deficit and UV-B radiation. Plant Sci. 213:98-105.

Blokhina, O., Virolainen, E., Fagerstedt, V. 2003. Antioxidants, oxidative damage and oxygen deprivation stress: a review. Ann. Bot. 91:179-194.

Blum, O.B., Gorobets, S.A., Blum, A.A. 2005. Effect of UV-B radiation on some cereals. BMC Plant Biology. 5 (Suppl 1):S4. DOI: 10.1186/1471-2229-5-S1-S4

Brazaitytė, A., Juknys, R., Sakalauskaitė, J., Šikšniaunienė, B., Januškaitienė, I., Dėdelienė, K., Sliesaravičius, A., Ramaškevičienė, A., Juozaitytė, R., Šlepetys, J., Kadžiulienė, Ž., Lazauskas, S., Duchovskis, P. 2006. Tolerance of photosynthetic pigments system of agricultural plants to ozone and UV-B radiation stress. Sodininkystė ir daržininkystė 25:14-24. (in Lithuanian)

Del Amor, F.M., Cuadra-Crespo, P. 2011. Gas exchange and antioxidant response of sweet pepper to foliar urea spray as affected by ambient temperature. Scientia Horticulturae 127:334-340. 
Ghasemi, S., Hossein, A., Afyuni, K.M., Hadadzadeh, H. 2013. The effectiveness of foliar applications of synthesized zinc-amino acid chelates in comparison with zinc sulfate to increase yield and grain nutritional quality of wheat. Eur. J. Agron. 45:68-74.

Gimeno, V., Diaz-Lopez, L., Simon-Grao, S., Martinez, V., Martinez-Nicolas, J.J., Garcia-Sanchez, F. 2014. Foliar potassium nitrate application improves the tolerance of Citrus macrophylla L. seedlings to drought conditions. Plant Physiol. and Biochem. 83:308-315.

Gupta, S.A., Berkowitz, G.A. 1987. Osmotic adjustment, symplast volume, and nonstomatally mediated water stress inhibition of photosynthesis in wheat. Plant Physiol. 85:1040-1047.

Hammad, S.A.R., Ali, O.A.M. 2014. Physiological and biochemical studies on drought tolerance of wheat plants by application of amino acids and yeast extract. Ann. Agric. Sci. 59:133-145.

Ibrahim, E.A., Ramadan, W.A. 2015. Effect of zinc foliar spray alone and combined with humic acid or/and chitosan on growth, nutrient elements content and yield of dry bean (Phaseolus vulgaris L.) plants sown at different dates. Scientia Horticulturae, 184:101-105

Januskaitiene, I. 2011. Effects of substrate acidity and UV-B radiation on photosynthesis of radishes. Central Eur. J. of Biol. 6:624-631.

Meier, U. 2001. Growth Stages of Mono- and Dicotyledonous Plants. Federal Biological Research Centre for Agriculture and Forestry. Berlin, Germany.

Nawaz, F., Ahmad, R., Ashraf, M.Y., Waraich, E.A., Khan, S.Z. 2015. Effect of selenium foliar spray on physiological and biochemical processes and chemical constituents of wheat under drought stress. Ecotoxicol. and Environ. Safety 113:191-200.

Newsham, K.K., Robinson, S.A. 2009. Responses of plants in polar regions to UVB exposure: a meta-analysis. Global Change Biol. 15:2574-2589.

Pospisilova, J. 2003. Participation of phytohormones in the stomatal regulation of gas exchange during water stress. Biologia Plantarum 46:491-506.

Poulson, M.E., Boeger, M.R.T., Donahue, R.A. 2006. Response of photosynthesis to high light and drought for Arabidopsis thaliana grown under a UV-B enhanced light regime. Photosyn. Res. 90:79-90.

Qaderi, M.M., Reid, D.M., Yeung, E.C. 2007. Morphological and physiological responses of canola (Brassica napus) siliquas and seeds to UVB and $\mathrm{CO}_{2}$ under controlled environment conditions. Environ. Exp. Bot. 60:428-437.

Reddy, K.R., Singh, S.K., Koti, S., Kakani, V.G., Zhao, D., Gao, W., Reddy, V.R. 2013. Quantifying corn growth and physiological responses to ultraviolet-B radiation for modeling. Agron. J. 105:1367-1377.

Shafeek, M.R., Ali, A.H., Mahmoud, A.R. 2016. Foliar application of amino acids and biofertilizer promote execution of broad bean plant (Vicia faba L.) under newly reclaimed land conditions. Int. J. PharmTech. Res. 9:100-109.

Sharma, P., Jha, A.B., Dubey, R.S., Pessarakli, M. 2012. Reactive oxygen species, oxidative damage, and antioxidative defense mechanism in plants under stressful conditions. Review article. J. Bot. pp. 1-26. https:// www.hindawi.com/journals/jb/2012/217037/

Singh, B.K. 1999. Plant Amino Acids: Biochemistry and Biotechnology. New York, USA. pp. 319-356.

Singh, S.K., Badgujar, G., Redd, V.R., Fleisher, D.H., Bunce, J.A. 2013. Carbon dioxide diffusion across stomata and mesophyll and photobiochemical processes as affected by growth $\mathrm{CO}_{2}$ and phosphorus nutrition in cotton. J. Plant Physiol. 170:801-813.

Singh, S.K., Reddy, K.R., Reddy, V.R., Gao, W. 2014. Maize growth and developmental responses to temperature and ultraviolet-B radiation interaction. Photosynthetica 52:262-271.

Syvertsen, J.M., Garcia-Sanchez, F. 2014. Multiple abiotic stresses occurring with salinity stress in citrus. Environ. Exp. Bot. 103:128-137.

Wettstein, von D. 1957. Chlorophyll Letale und der Submikroskopische Formweschsel der Plastiden (Chlorophyll lethals and submicroscopic morphological changes in plastids). Exp. Cell Res. 12:427-432 (in German).

Yadav, G., Srivastava, P.K., Parihar, P., Tiwari, S., Prasad, S.M. 2016. Oxygen toxicity and antioxidative responses in arsenic stressed Helianthus annuus L. seedlings against UV-B. J. of Photochem. and Photobiol. B: Biology 165:58-70. 